\title{
Development of more productive and persistent lucerne by selection under frequent cutting
}

\author{
R.G. PURVES ${ }^{1}$ and R.B WYNN-WILLIAMS ${ }^{2}$ \\ ${ }^{1}$ AgResearch, PO Box 60, Lincoln \\ ${ }^{2}$ Crop and Food Research, Private Bag 4704, Christchurch
}

\section{Abstract}

The area of luceme (Medicago sativa L.), regarded as the best adapted legume for dry areas of New Zealand, has declined by $67 \%$ over the last 2 decades. The major reason for the decline has been the effect of pests, diseases and poor grazing management on productivity and persistence. The development of disease- and pest-resistant cultivars has allowed plant breeders to investigate methods for developing grazing-tolerant lucernes. It has been suggested that frequent cutting is harder on plants than grazing and that it could be used to rapidly identify the survival characteristic of breeding lines. Lines surviving cutting every 4 weeks for 2 seasons have been selected at Lincoln. To evaluate the breeding method these selected lines were compared with their parents, under 4weekly cutting (frequent), 8-weekly cutting (infrequent) and frequent grazing. Frequent grazing was less severe on plants than frequent cutting and evaluation by this treatment was discontinued after 3 years. There was a trend towards increased production through selection under-both-frequent-and-infrequent-cutting-and there appeared to be line differences in response to selection. Persistence of lines after 7 years of frequent and infrequent cutting was significantly improved by selection for most lines. The different degrees of improvement between lines indicate that lines responded differently to selection. Cutting frequency had little effect on the final plant numbers of lines. The differences between cultivars and lines can be attributed to disease and pest resistance and adaptability of lines. The trial showed that selecting plants tolerant of frequent cutting can improve production and persistence.

K eywords: frequent cutting, grazing, Medicago sativa, persistence, production, selection

\section{Introduction}

Lucerne (Medicago sativa L.) is a forage legume well adapted to the dry east coast regions of New Zealand.
However, the area of luceme grown in New Zealand has declined from 220000 ha in 1978 to 72000 ha in 1992 (Statistics New Zealand). The decline in area has been due to changing land use in some traditional luceme growing areas but, more importantly, due to the effects of pests, diseases and poor grazing management which have reduced lucerne's production and persistence. Plant breeding over the past 20 years has concentrated on developing cultivars with resistance to pests and diseases. With the development of resistant cultivars and breeding lines, the Lincoln breeding programme is beginning to develop lucerne that is more productive and persistent when frequently defoliated. This should make grazing management of luceme easier on-farm

Poor persistence under intensive grazing has limited luceme's use as a pasture plant. However, in New Zealand most luceme is grazed for part or all of the growing season. To persist under grazing a defined rotational grazing management was developed from principles of cutting management based on cyclical patterns of root carbohydrate storage and use within the plant. Persistence and productivity is strongly related to the duration of grazing and the interval -between-grazings ${ }^{-}$(spelling).-Iversen-(1967) ${ }^{-}$recommended 4 days' grazing followed by 36 days' spelling as the best grazing management. To apply this system requires a number of paddocks and intensive stock management. To reduce the intensity of rotational grazing, Janson (1982) concluded that while correct spelling is important to maintain persistence and productivity, grazing duration is of less importance providing it is no longer than 15 days. Farmers have found strict rotational grazing difficult because of the differing requirements of the plant and the grazing animal. In Australia, Lodge (1991) concluded that in spite of recommendations luceme stands are commonly used opportunistically, to maximise animal productivity, depending on rainfall and the feed supply from other pastures. This has been compounded by a reluctance to subdivide paddocks to enable easy grazing management. From general 'over the fence' observations, poor grazing management, with continuous set stocking for long periods, is common in Canterbury (Palmer 1982). This could also be concluded for grazing of luceme in much of New Zealand. 
The effect of poor grazing management on luceme is well documented. Keoghan (1994) found that grazing mismanagement resulted in reduced yields, reduced competitiveness with weeds and eventual stand decline. It could also be speculated that stands of poor vigour may be more susceptible to diseases especially crown and root rots. In combination with poor grazing management and climatic stresses these diseases will contribute to the stand decline.

The development of a greatly improved grazing luceme has been seen as the key to increasing its usage as a pasture legume. Persistence and production of luceme under grazing has been an objective of a number of overseas breeding programmes over the last 50 years (Heinrichs 1978). The most common approach has been to select for either creeping rooted or rhizomatous types which have low set crowns that avoid grazing damage. The creeping morphology is derived from the Medicago falcata subspecies. The usefulness of cultivars of this type has been limited by their low yield potential (Palmer 1967), varying expression of the trait in differing soil types (Palmer pers comm.), slow recovery rate after grazing (Busbice \& Hanson, 1969) and varying reports on their ability to persist under intensive grazing (Leach 1969b; Leach 1970). A more recent approach in the development in the breeding of grazing lucemes has been to subject breeding material to management treatments similar to the intended target system. Leach (1971), for example, suggested that frequent cutting could be used as a rapid method of determining the survival characteristics of lines. Heinrichs (1974) found that frequent defoliation by mechanical means was harder on plants than grazing by animals and could be used to measure persistence of lines providing that final assessments of new cultivars are made using animal grazing trials. Frequent cutting is being used by the Lincoln breeding programme as a method to identify and develop germplasm tolerant of frequent defoliation. Results from a trial established to evaluate this method are presented in this paper.

\section{$M$ aterials and methods}

Eight cultivars and disease and pest resistant synthetic populations were established in plots at Lincoln in October 1981. These were cut to $2.5 \mathrm{~cm}$ using a forage harvester every 'four weeks during the 1982/83 and 1983/84 growing seasons. Surviving plants from each population were selected during spring of 1984 and allowed to inter-pollinate in separate isolations.

A trial comparing the eight selected lines with their parents was sown in a Templeton silt loam at Lincoln during October 1985. The trial was a split plot design, with 3 management treatments as mainplots, 8 selected lines and 8 parents as subplots and 3 replicates. The 3 management treatments consisted of cutting every 4 weeks (frequent), cutting every 8 weeks (infrequent) and grazing at 80 ewes/ha for 4 weeks and spelling for 4 weeks. Treatments began at the beginning of the 1986/87 season. Cutting treatments continued until the end of the 1992/93 season but the grazing treatment was discontinued after 3 years.

Herbage yield of lines was measured after treatments had been applied for 1 year. Plots were cut and weighed through one complete 8-week growth cycle (cut 13/1/88 and 17/2/88 for frequent, 17/2/88 for infrequent). All cutting treatment plots were cut and weighed again for the final spring cut on $26 / 10 / 93$. Persistence of lines was determined during December 1993 by digging two $0.5 \mathrm{~m}^{2}$ quadrats per plot and recording plant numbers. Yield data were analysed as a split plot randomised block with LSDs calculated for comparison of means. Plant numbers were analysed using a square root transformation and results are presented as back-transformed means.

\section{Results and discussion}

No data from the grazing treatment was included in the analysis. Grazing was discontinued after 3 years when it became apparent from an early stage that the grazing was less severe on theplants than frequent cutting. This confirms the findings of Heinrichs (1974). Comparisons between plots was not possible as uneven grazing and stock camps resulted in some plots being treated more harshly than others. For this reason, rapid screening of plants using grazing animals could be seen as less reliable than frequent cutting.

Janson's (1982) conclusion that. there is scope to manipulate grazing duration for periods longer than the existing accepted duration of 4-6 days was controversial at the time. Palmer (1982) considered that Janson's result of having animals on luceme for periods of up to a fortnight without harming the luceme was very important, but extending grazing duration could not be recommended until these findings could be verified under differing stocking rates and conditions. In our trial, the finding that grazing for 4 weeks was less severe than 4-weekly cutting provides further evidence that there may be scope to extend grazing duration providing the period of spelling is correct.

On average, the selections produced initially 50\% and $28 \%$ more dry matter than the parents under frequent and infrequent cutting respectively (Table 1). The differences were significant only for Pr.521 in the frequent cut treatment and Rere in the infrequent cut 
treatment. Variation between plots was large at this early stage of the trial, exacerbated by parts of the trial becoming. infected with stem nematode (Ditylenchus dipsaci Kuhn.). This gives some explanation as to why such large yield differences between the selections and parents was not statistically significant. It is difficult to determine if one or more lines responded more to selection than other lines because of their different levels of resistance to the nematode. However, the greater improvement of AS13R compared with Aragon under frequent cutting may indicate a difference as both are resistant to stem nematode. The trend towards increased production through selection remained until the final cut. The difference between selections and parents was significant for Moapa and AS13R under frequent cutting and Pr.521 and 3BC2A1 under infrequent cutting.

Table 1 Initial and final dry matter yields ( $\mathrm{kg} / \mathbf{h a})$.

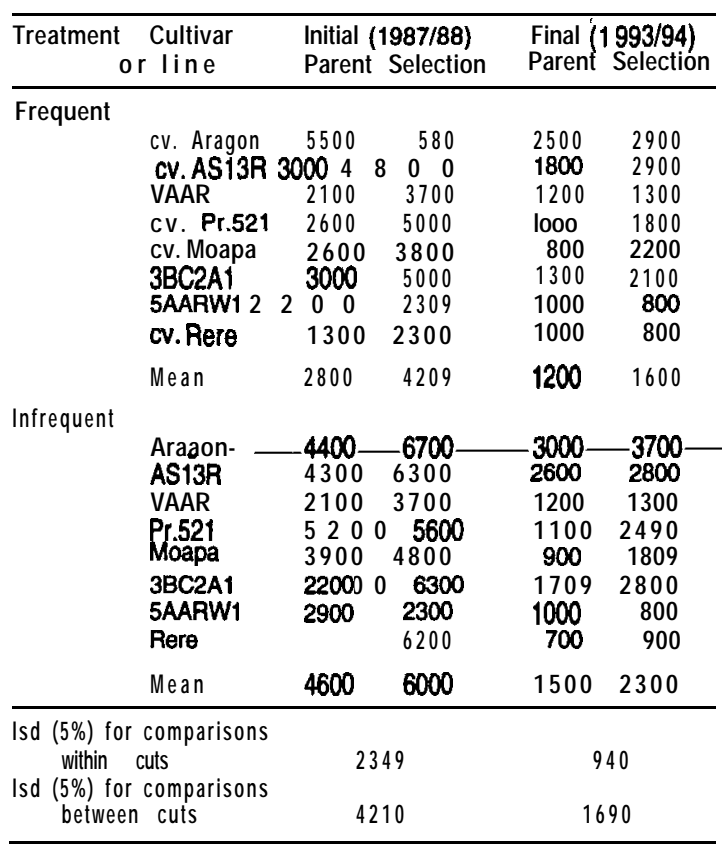

The yields from the final cut reflect the persistence of lines as do the final plant numbers. On average, selections had 2 times more plants surviving after 7 years of both frequent and infrequent cutting (Table 2). Under frequent cutting all lines except Rere were improved significantly by selection and all but Aragon and 5AARW1 under infrequent cutting. A significant $(\mathrm{P}<0.01)$ cultivar $\mathrm{x}$ selection interaction for the transformed plant numbers confirmed that lines responded differently to selection and these responses may vary under different cutting treatments. It highlights the usefulness of frequent cutting as a technique. to rapidly improve the persistence of breeding lines.

Table 2 Back-transformed mean plants $/ \mathrm{m}^{2}$.

\begin{tabular}{|c|c|c|c|c|}
\hline \multirow[t]{2}{*}{ Cultivar } & \multicolumn{2}{|c|}{ Frequent cut } & \multicolumn{2}{|c|}{ Infrequent cut } \\
\hline & Parent vs & Selection & Parent vs & Selection \\
\hline $\begin{array}{l}\text { Aragon } \\
\text { AS13R } \\
\text { VAAR } \\
\text { Pr.521 } \\
\text { Moapa } \\
\text { 3BC2A1 } \\
\text { 5AARWI } \\
\text { Rere }\end{array}$ & $\begin{array}{l}75 \\
21 \\
14 \\
14 \\
5 \\
8 \\
7 \\
2\end{array}$ & $\begin{array}{c}97 \cdot \\
58 \cdot \square \\
43 \cdot \square \\
33: \\
31 \cdot \square \\
24 \cdot \square \\
15 \cdot \\
6 \mathrm{~ns}\end{array}$ & $\begin{array}{l}73 \\
42 \\
11 \\
16 \\
6 \\
14 \\
11 \\
1\end{array}$ & $\begin{array}{l}90 \mathrm{~ns} \\
68 * \\
26 . \\
47 . \\
25 . \\
50 . \\
11 \mathrm{~ns} \\
12 . *\end{array}$ \\
\hline Mean & 18 & $38 \cdot \square$ & 22 & 41. \\
\hline
\end{tabular}

Of the parents only Aragon had more than 30 plants $/ \mathrm{m}^{*}$ after 7 years of frequent cutting. Five of the selections had more than this number of plants, which was considered by Palmer \& Wynn-Williams (1976) to be the number of plants required for full production inestablished stands. A similar trend occurred in the infrequent cut treatment. This indicates that selection by frequent cutting is resulting in better persistence and, given correct spelling, should improve production.

The final plant numbers for both selections and parents lines were the same in each cutting treatment. Differences between lines for both yield and plant numbers at the conclusion of the trial were significant (P<0.01). and can be attributed to differences in disease and pest resistance and overall adaptation of the lines.

\section{Conclusion}

Frequent defoliation by cutting over a relatively short period of time can be used to select plants for improved production and persistence and lines selected in this manner appear to be superior under both frequent and infrequent cutting. Frequent cutting is a better method of quickly identifying superior lines than is frequent grazing. Second-cycle selections of plants surviving the frequent cut treatment have been made and, as suggested by Heinrichs (1974), will be evaluated under grazing. Cultivars with tolerance to frequent cutting or grazing will improve persistence of luceme stands during periods of poor grazing management.

\section{ACKNOWLEDGEMENTS}

The authors wish to thank Miles Rae and Trevor Ellis for their technical assistance and to Leslie Hunt for statistical analysis of the trial data. 


\section{REFERENCES}

Busbice, T.H.; Hanson, C.H. 1969. Selection for improving creeping-rooted characteristics in alfalfa. Crop science 9: 244-246.

Heinrichs, D.H. 1974. Breeding grasses and legumes for pasture in Canada. Proceedings XII International Grassland Congress Vol.1 Part 1: 223-242.

Heinrichs, D.H. 1978. The future for alfalfa for pasture in dry regions and research requirements. Report 26th Alfalfa Improvement Conference: 4-9.

Iversen, C.E. 1967. Grazing management of luceme. pp. 129-133 I The Lucerne Crop Ed. R.H.M Langer. Reed, Wellington.

Janson, C.G. 1982. Lucerne grazing management research. pp. 85-90 In Lucerne for the 80's. Ed. R.B. Wynn-Williams, Agronomy Society of New Zealand, special publication No. 1.

Keoghan, J.M. 1994. Lucerne management for the Maniototo. pp. 19-26 In Managing the Maniototo. Ed. D. Ryde, AgResearch, Lincoln.

Leach, G.J. 1969b. The survival in South Australia of Hunter River, African and creeping lucemes after extended periods of severe grazing. Australian journal of experimental agriculture and animal husbandry 9: 5 17-520.
Leach, G.J. 1970. An evaluation of lines at the Waite Agricultural Research Institute, South Australia. Australian journal of experimental agriculture and animal husbandry 10:53-61.

Leach, G.J. 1971. The yield and survival of luceme lines in the upper south-east of South Australia. Australian journal of experimental agriculture and animal husbandry 11: 186-193.

Lodge, G.M. 1991. Management practices and other factors contributing to the decline in persistence of grazed luceme in temperate Australia: a review. Australian journal of experimental agriculture 31: 713-24.

Palmer, T.P. 1967. Lucerne breeding in New Zealand. pp. 85-93 In The Lucerne Crop. Ed. R.H.M. Langer. Reed, Wellington.

Palmer, T.P. and Wynn-Williams, R.B. 1976. Relationships between density and yield of luceme. NZ journal of experimental agriculture 4: 71-77.

Palmer, T.P. 1982. Lucerne for the 80's. Conclusions from the symposium. pp. 129-131 In Lucerne for the 80's. Ed. R.B. Wynn-Williams. Agronomy Society of New Zealand, special publication No. 1. 